\title{
The system of strategic planning as an institutional basis for ensuring sustainable development of territories under Industry $\mathbf{4 . 0}$
}

\author{
Irina Rakhmeeva ${ }^{*}$, Ivan Antipin, and Olga Ivanova \\ Ural State University of Economics, Department of Regional, Municipal Economics and Governance, \\ 620144, 8 Marta St., 62, Ekaterinburg, Russia
}

\begin{abstract}
Technological revolution and growing social, economic, ecological, and biological threats make the topic of sustainable development increasingly relevant. Having examined the development strategies of the subjects of the Russian Federation, we identify three strategies of industrial development currently pursued by the Russian regions: extractive growth, inclusive reindustrialization, and new industrialization. In line with the specified strategic directions, the systems of objectives are structured. The analysis of the strategic planning documents of the RF subjects located within the Ural macroregion revealed that in accordance with the suggested classification, they adopt the policy of industrial development. To shift the policy focus towards the new industrialization, corrective measures are proposed. The research proves that modern system of strategic planning should be flexible and adaptable, in addition to be based on the uniform rules of strategizing.
\end{abstract}

\section{Introduction}

The problem of sustainable development has been a concern of economists for more than half of a century. Given the turbulence of the world economy and global crises of the $21^{\text {st }}$ century, the factors of sustainable development have to be rethought and new ways to ensure it have to be searched for. The new reality is being formed by the digitalization of all activities, post-pandemic restrictions, a critical level of social instability and environmental threats.

The objective of formulating a competent industrial policy for regions is important for ensuring the competitiveness of the constituent entities of the Russian Federation in terms of technological and economic development under the fourth industrial revolution. Economists acknowledge that the goal of achieving a technological breakthrough and Russia's jumping onto "innovative track" remains unresolved despite a long period of attempts.

The research aims to suggest approaches to constructing a system of strategic priorities in the industrial development of the Russian regions to shift the trajectory of their development towards a more active new industrialization.

* Corresponding author: smartreg66@gmail.com 
With this end in view, the paper adapts the content of the sustainability concept to the new reality, classifies typical approaches to the industrial development of regions, structures the corresponding systems of objectives, studies the practice of the subjects of the Ural macroregion and formulates corrective measures.

The study is based on a comprehensive analysis of strategies for socioeconomic development of the constituent entities of the Russian Federation located within the Ural macroregion.

\section{Methodology}

For more than 30 years, the concept of sustainable development has been used quite often in program and strategic documents of various levels: international, national, regional, municipal, and corporate. The concept was introduced into economic theory at the early $20^{\text {th }}$ century by the Russian zemstvo ${ }^{1}$ statistician, politician and economic geographer Nikolay Oganovsky in the context of the historical study of the laws governing the evolution of agriculture and sustainable development of productive forces [1]. Oganovsky's original concept had been decades ahead of international discussions on the new concept, which resulted in the prominent Report of the World Commission on Environment and Development: Our Common Future [2] published in 1987 that officially proclaimed the need to ensure a balanced solution to address socioeconomic issues and problems of preserving a healthy environment, natural resource potential in order to meet the needs of present and future generations of people. For the first time, there was given the definition of sustainable development of a territory which has now become widespread: sustainable development of a territory is development that meets the needs of the present without compromising the ability of future generations to meet their own needs.

Numerous outstanding Russian researchers, including Abalkin [3], Tatarkin [4], Kuklina [5] and many others contributed to the analysis of the concept of sustainable development in the context of various theoretical issues, but its immanent essence has remained practically unchanged. At the same time, the diversity of existing approaches to defining sustainable development is explained by the multiplicity of objects to which the provisions of this concept are applied.

We believe that with regard to sustainable development of the regional socioeconomic system, Kiseleva offered the most complete and universal definition, interpreting it as a controlled process of intensive reproduction of factors of production and material wealth due to the balanced development of the system-forming components of the regional socioeconomic system that ensure its progressive development [6]. This definition emphasizes the fact that maintenance of the sustainable development of a region is based on the balance of the system-forming components (subsystems), which encompass society, nature, economy, and innovation. Fig. 1 shows authors' own representation of the interactions between these components in the regional space.

\footnotetext{
${ }^{1} \mathrm{TN}$ : an institution of local government in prerevolutionary Russia.
} 


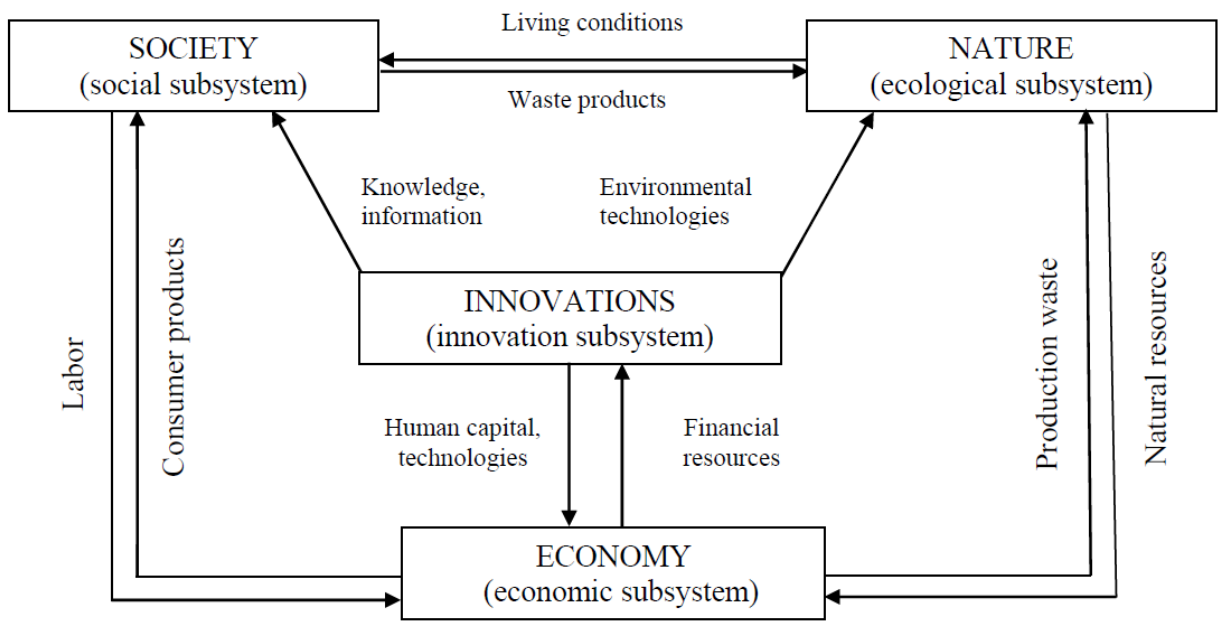

Fig. 1. Interactions between the components (subsystems) of sustainable development [7].

Within the concept of sustainable development, the economic subsystem should be considered as a holistic set of various productive forces distributed across industries, territories, and forms of ownership. It can be represented in the form of an organized field of interactions between economic entities, which are bound by strong economic relations, and feature stable connections and forms of behaviour. The social subsystem unveils the stratification of actors involved in economic relations and their interaction at the individual and group levels. The ecological subsystem is built up by two components: the community of living organisms and their habitat. The innovation subsystem consists of the process and results of labor in the field of advancing scientific knowledge and creating innovations.

At the same time, the concept of sustainable development does not provide a specific answer to the question of how exactly the "balanced development" of the above-mentioned components should be ensured. This answer, we believe, will be unique for each region, and the mechanism for ensuring balanced development should be specified in the strategy for socioeconomic development in the region. It is not difficult to notice that the components of sustainable development make up the key sections of the strategy for socioeconomic development of any region. Thus, the institutional role of the strategic planning system lies precisely in defining and maintaining the balance of subsystems that allows the region to develop steadily along a progressive trajectory.

According to the generally accepted definition, institutions are a set of rules reflected in formal and informal constraints and structuring human interactions [8]. Taking into account that the system of strategic planning constitutes the institutional basis for the sustainable development in the space of regions, this basis should take a form containing specific principles and rules of, approaches and requirements to organization of the process of developing, implementing and monitoring the results of the implementation of strategic documents.

The analysis of modern approaches to strategic planning indicates that the overwhelming part of the research is based on the recognition of strategic planning as an effective mechanism and tool for managing territorial development, as well as the basis for correlating the internal capabilities and resources of the territory with the influence of external factors. 
One domain of strategic development of modern cities and regions, including in the context of the fourth industrial revolution, is innovative development. The need to develop theoretical, methodological, and applied aspects of the strategic (including innovative) development of territories in order to enhance their competitiveness, sustainability and security is rationalized by a set of interrelated circumstances [9]:

first, the development of the modern world is based on progress, among others, in scientific, technological, and innovation spheres. This process is characterized by significant dynamics, the speed of changes that are generated by the growing globalization of the economic, political, and socio-cultural life of various countries and regions regardless of their level of development;

second, in developed countries, the developers of industrial, scientific, technological, and innovation policy attach increasing importance to those areas that are focused on the growth of public goods, or the welfare of society, as well as on their sustainability. These are, first of all, activities aimed at promoting health, information and communication technologies, all types of production and services, and environmental protection as the basis of high-quality life;

third, at present, the necessity to intensify and improve innovative development is obvious. The regions and cities of the Russian Federation will have to sensibly decide on the priorities of their strategic development, as well as the mechanisms for achieving them.

Consider the practice of adapting strategies for socioeconomic development of regions located within the Ural macroregion to the conditions imposed by the fourth industrial revolution.

\section{Results}

\subsection{Strategic directions of industrial development under Industry $\mathbf{4 . 0}$}

A review of the literature allows us to generally characterize reindustrialization as a return to the industrial model of the economy that implies an increase in the share of industry in GRP. This process is implemented mainly by the expansion of traditional industries, which can be maintained by extractive (increase in resource extraction) or inclusive factors (modernization of production, resource conservation, increasing the depth of processing of raw materials $[10,11])$. We classify the first approach to reindustrialization as extractive industrial growth, and the second one as inclusive reindustrialization. However, economists point to the exhaustion of the potential of traditional technologies and a drop in the return on investment in them.

The third approach to regional industrial policy is new industrialization, which is fundamentally different from the first two ones in its orientation towards increasing the share of the products belonging to the new technological waves in the output structure and modernizing traditional industries on the basis of new management models and technologies offered by Industry 4.0.

The objectives of the industrial development in regions in the selected strategic directions are decomposed and structured by the authors in Fig. 2. 


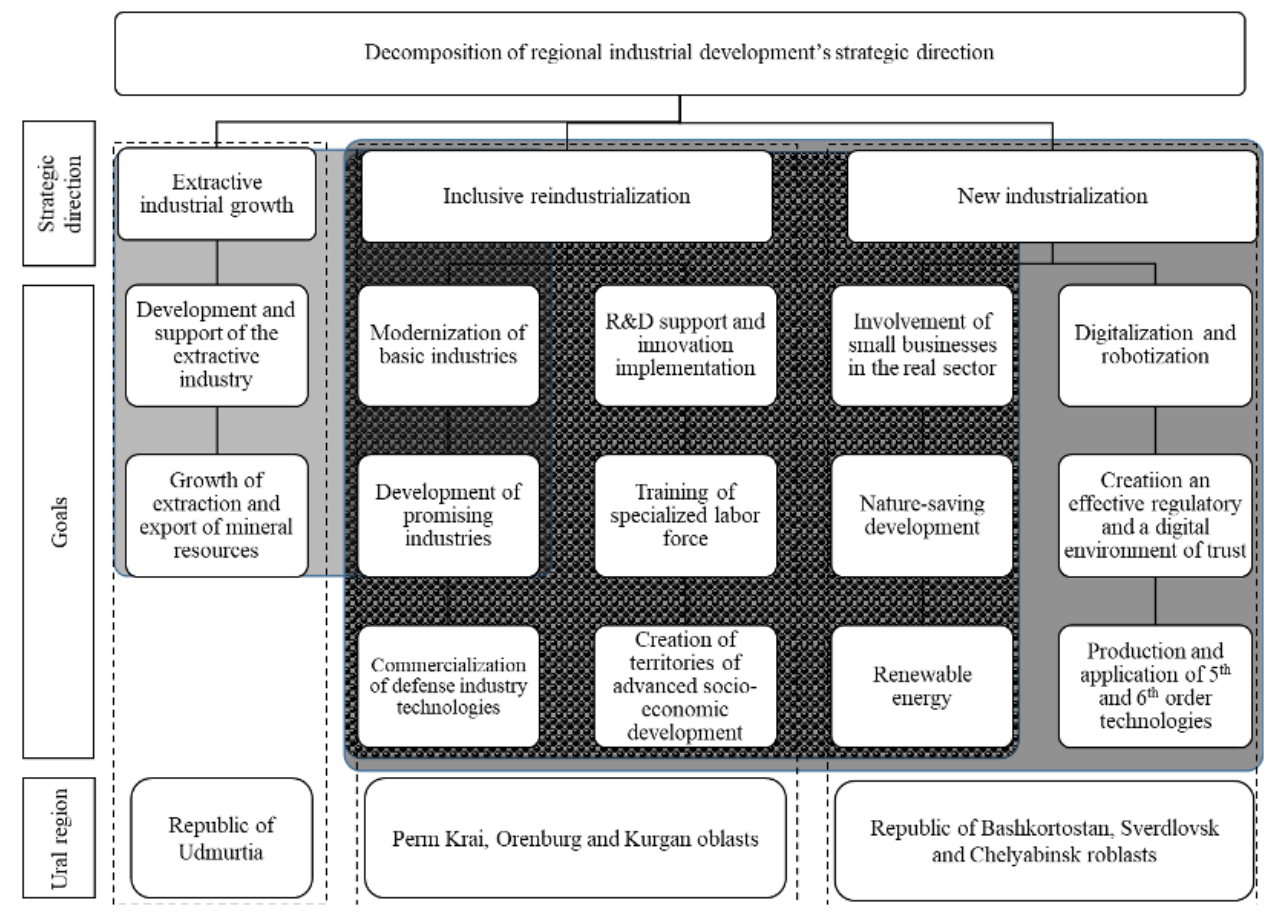

Fig. 2. Decomposition of the objectives in line with the directions of regional industrial development.

A number of objectives are common to several types of industrial policy. For instance, the modernization of basic industries is relevant for all the three: to extractive industrial growth (to promote the efficiency of the mining sector), inclusive reindustrialization (to increase the depth of processing of raw materials), and new industrialization (to cover all industries with new technologies).

Inclusive reindustrialization implies a reduction in the extraction of natural resources with a transition to high value added production, renewable energy, green economy, and sustainable development through resource conservation and increased recycling of waste. Like the new industrialization, it is based on the support of science and innovation, training of qualified personnel, creation of territories of advanced socioeconomic development in regional space, and involvement of small and medium-sized businesses in the real sector.

Yet new industrialization has a number of specific objectives. In particular, these include the production of goods and technologies of the $5^{\text {th }}$ and $6^{\text {th }}$ technological waves, their introduction at enterprises of a region, digitalization and robotization of production as well as some other economic processes. In terms of the evolution of the regional regulatory environment, new industrialization means forming an effective legal framework and a digital environment of trust.

The industrial policy of the region manifests itself through the strategic documents of the subject of the Russian Federation, where the objectives and target indicators of industrial development are fixed [12]. The absence of specific target indicators in the strategy leads to low efficiency of its implementation, the impossibility of assessing the actual achievement of goals and a decrease in the motivation of the executive authorities of the subjects of the Russian Federation. 


\subsection{The practice of the Ural regions in the formulation of development strategies in the context of Industry 4.0}

We examined the strategies for socioeconomic development of the subjects located within the Ural macroregion with regard to the inclusion of the industrial development objectives in line with the three identified types (Fig. 2). Based on the analysis, we found out the following.

The strategies of all subjects of the Ural macroregion reflect the objectives of promoting promising, high-tech industries, training specialized personnel (with the exception of the Kurgan oblast), supporting science and innovation, sustainable, nature and resource-saving development (with the exception of the Republic of Udmurtia) as well as fully or partially cover the issues of creating the territories of advanced social and economic growth.

The strategies of the Chelyabinsk oblast and the Republic of Bashkortostan pay attention to improvement of the environmental literacy of the population and digital development. The manufacture of products belonging to the $5^{\text {th }}$ and $6^{\text {th }}$ technological waves accompanied by the specification of types of products is supported in the Sverdlovsk, Chelyabinsk, and Orenburg oblasts, and the Republic of Bashkortostan. The only Chelyabinsk oblast defines the objectives of working on the regulatory environment of the new economy under the fourth industrial revolution.

The Republic of Bashkortostan, the Sverdlovsk and Chelyabinsk oblasts form a favorable regulatory environment, and are focused on the processes of new industrialization. The system of their target indicators is thoroughly worked out, elaborates on the practical mechanisms for accomplishing the objectives and contributes to the promotion of new technological waves in these territories.

The strategy for socioeconomic development of the Republic of Udmurtia considers the fall in oil prices and demand as well as barriers to expanding the export of raw materials to be the core problem and risk, and highlights the role of the price factor in regional development. Oil production is seen as the key sector of the economy, and its support and development is assigned a priority.

With regard to indicators of industrial development, the Perm krai and the Republic of Udmurtia, as well as in many respects the Orenburg oblast, do not set specific values, and this reduces the efficiency of the strategies' implementation.

Therefore, the Republic of Udmurtia demonstrates an orientation towards extractive industrial growth in its strategic documents, the Perm krai, Orenburg and Kurgan oblasts move towards inclusive reindustrialization. Their regulatory environment can be characterized as an unfavorable one for technological breakthroughs. These regions should adjust the trajectory of regional development towards new industrialization, and better start with the creation of an efficient regulatory environment and the formulation of a comprehensive strategy in accordance with the objectives of new industrialization structured in the study.

\section{Discussion}

We share the viewpoint of high importance of regional policy to the successful implementation of new industrialization under Industry 4.0 [13]. Having analyzed Norway's institutional response to sustainable development, Sverdrup concluded that environmental considerations have to a large extent been institutionalized into the existing political system due to the United Nations Conference on the Environment and Development [14]. $\mathrm{Ng}$ argued that given the central role of the government in directing growth and development in East Asia, the sustainability policies, rhetoric and actions in the 
cities are a function of the perception of the concept of sustainable development by the government [15].

Our attempt to systematize existing approaches to establishing strategic goals of the regional industrial development in order to switch to the trajectory of sustainable development has prospects to be advanced further in the research of modern regional economists.

The complexity of the system of strategic priorities of sustainable development dictates the necessity to apply a multidisciplinary approach [16]. For example, Cuiying showed that combining sustainable development strategies with Deng Xiaoplng's theory on socialist construction produced a great positive effect on China's economy [17].

A significant factor behind the efficiency of strategic planning as an institution is public accountability of government authorities together with imposition of the corresponding disciplinary measures. However, Australian group of economists revealed few formal compliance-based accountability mechanisms in relation to government [18].

\section{Conclusions}

Five years ago economists debated whether global stagnation is the new normal or a crisis point [5]. Today, it is obvious that the new reality implies turbulence of external impacts in terms of their composition, strength and directions together with the conditions indicated in the paper. Thus, a modern strategic planning system should be flexible and adaptable, in addition to be based on the uniform rules of strategizing.

When determining the composition of the priority strategic directions for the development of a territory, it is necessary to combine them in such a way that the achievement of the results of their implementation could ensure the achievement of the main goal of the strategy. Taking into account that the main goal is to improve the quality of life, then the choice of strategic directions needs comprehensiveness that guarantees the development of human potential, an economy (including industry and innovation according to the selected specializations and priorities, which can be separate areas due to their importance), engineering, transport and social infrastructures, environmental security, and increase in the comfort of living and staying in a territory.

In view of that, the processes of strategic planning and strategic management should be improved, in particular, the design of strategies for socioeconomic development of various territories, including mechanisms for their implementation. At the present stage of development of Russian science, the researchers are interested in various issues of regional strategic planning [19], and more specifically in their methodological support [20].

Currently, the Russian Federation encounters the necessity to adopt uniform rules of strategizing for territories of all hierarchical levels, which will ensure the creation of a unified strategic planning system as an institutional basis for sustainable development of territories, including in the context of the fourth industrial revolution.

\section{Acknowledgment}

The reported study was funded by RFBR, project number 20-010-00824 «Incremental approach to the formation and implementation of socio-economic development strategies for the Russian Federation regions of different hierarchical levels: uniform rules of strategizing». 


\section{References}

1. N. P. Oganovskyi, The regularity of agrarian evolution. Part 1. Theories of capitalist development. The general course and phases of agrarian evolution (1909)

2. Report of the World Commission on Environment and Development: Our Common Future (1987)

3. L. I. Abalkin, Voprosy Ekonomiki, 12, 4-13 (1994)

4. A. I. Tatarkin, S. N. Kotlyarova, Economy of Region, 3 (35), 18-26 (2013)

5. E. A. Kuklina, O. V. Starikova, Journal of Applied Economic Research, 15 (3), 401419 (2016)

6. N. N. Kiseleva, Sustainable development of the region: research methodology, models, management (2008)

7. O. G. Pozdeeva, O. Yu. Ivanova, Regional economics: a short course of lectures (2017)

8. D. North, Institutions, institutional change and economic performance (1990)

9. Ya. P. Silin, Ye. B. Dvoryadkina, I. A. Antipin, Upravlenets - The Manager, 9 (6), $2-$ 16 (2018). Access mode: DOI 10.29141/2218-5003-2018-9-6-1

10. A. A. Gibadullin, M.I. Sadriddinov, Z.M. Kurbonova, Y.N. Shedko, V.V. Shamraeva, IOP Conference Series: Earth and Environmental Science, 421 (3), 032051 (2020)

11. A. Zaytsev, N. Dmitriev, D. Bunkovsky, Academy of Strategic Management Journal, 19 (5), 1-14 (2020)

12. I. Rakhmeeva, I. Antipin, E3S Web of Conferences : TRESP 2021, 05004 (2021)

13. Y. Shedko, E. Plisetsky, A. Ksenofontov, N. Alenteva, S. Amarsanaa, IV Int. Sc. Conf. "Competitiveness and the development of socio-economic systems", European Proceedings of Social and Behavioural Sciences, 105 (2020). Access mode: DOI 10.15405/epsbs.2021.04.94

14. L. A. Sverdrup, Environmental Politics, 6, 1 (1997)

15. M. K. Ng, Journal of Comparative Policy Analysis: Research and Practice, 9, 4 (2007)

16. G. Shao, F. Li, L. Tang, International Journal of Sustainable Development \& World Ecology, 18, 3 (2011)

17. Zh. Cuiying, Chinese Journal of Population Resources and Environment, 2, 2 (2004)

18. A. Sumarwan, B. Luke, C. Furneaux, Social and Environmental Accountability Journal (2021). Access mode: DOI 10.1080/0969160X.2021.1952886

19. Yu. G. Lavrikova, A. A. Pryadein, I. A. Antipin, A. V. Suvorova, Economic and Social Changes: Facts, Trends, Forecast, 6, 214-235 (2016). Access mode: DOI 10.15838/esc/2016.6.48.12

20. N. M. Surnina, Ye. A. Shishkina, Upravlenets - The Manager, 4 (1), 56-63 (2013) 